\title{
The Application of Potentiometric Methods in Determination Total Organic Carbon Content of Soil
}

\author{
Yohandri Bow $^{\# 1}$, Hairul ${ }^{\# 2}$, Ibnu Hajar* \\ ${ }^{\#}$ Chemical Engineering Department, State Polytechnic of Sriwijaya, Palembang 30139 Indonesia \\ E-mail: ${ }^{2}$ andre_bow@yahoo.com, ${ }^{2}$ hairulroni@gmail.com \\ *Electrical Engineering Department, State Polytechnic of Sriwijaya, Palembang 30139 Indonesia \\ E-mail: ibnubaray@gmail.com
}

\begin{abstract}
Potentiometric method is one method that is widely used to determine the content of certain ions in a solution, but have not been widely applied to the analysis of soil samples. In this research apply the potentiometric methods for the determination of total organic carbon content of solids affected by oil contamination using $\mathrm{CO}_{2}$ selective electrode as indicator electrode. The principle of the determination of total organic carbon content of the soil is the total organic carbon change into $\mathrm{CO}_{2}$ and subsequently measured concentration of $\mathrm{CO}_{2}$ generated by potential changes electrodes shown by $\mathrm{CO}_{2}$ selective electrode. The concentration of $\mathrm{CO}_{2}$ is obtained proportional to the concentration of total soil organic carbon. Before application for the measurement, the $\mathrm{CO}_{2}$ selective electrode must be characterized. The investigation showed that the response time of the electrode was 3 minutes, limit of detection $5 \times 10^{-4} \mathrm{M}$ and the optimum $\mathrm{pH}$ of the solution was 4 and it was stable for 40 seconds because the $\mathrm{CO}_{2}$ was lost to the air. Total soil organic carbon content of soil was detected in the affected oil stain ranges from $0.05 \%$ to $0.01 \%$. For comparison the feasibility of the measurement results, compared with the measurement by titrimetric method. The measurement results of both methods showed that the potentiometric method can be used to determine the total organic carbon content of the soil with the result that a more accurate estimated compared with titrimetric methods.
\end{abstract}

Keywords - potentiometric; ion selective electrode; total organic carbon content of the soil

\section{INTRODUCTION}

The content of organic matter in the soil is very influential on physical, chemical and biological soil which further affect the level of soil fertility. One of the main components of organic matter constituent is carbon element, so the knowledge of the carbon content in the soil can provide information to the level of soil fertility[1].

Beings associated with the element carbon in the soil, the determination of carbon content of soil organic carbon content based on the total. Several researchers have carried out measurements of total organic carbon content of the soil with the conventional method, which is the usual titrimetric method. This method is a standard method that has long been used in the analysis of the soil because it is relatively simple, fast and cheap. Apart from these advantages, titrimetric method has fundamental weaknesses especially in the determination of the end point of the titration. This weakness is often the case in an analysis that resulted in measurement typically results obtained, in addition to the weaknesses due to errors that occur at different stages of the process[2].
Based on these reasons, it is necessary to have an alternative method that can be applied in the determination of total organic carbon content of the soil. One of the methods that can be applied is the potentiometric method using $\mathrm{CO}_{2}$ as an electrode selective.

Electrode is an element that is often called a sensor that can capture the physical and chemical phenomena that is then converted into an electrical signal in the form of electrical current or voltage electrical. Potentiometric electrodes are generally used to measure the potential of galvanic cells. Potential of galvanic cells depends on the activity of the various species that undergo reaction in the cell. Equation expressing this relationship is called the Nernst equation[8].

In the oil pipeline system leaks often occur which could result in contamination of groundwater in the area. Impact of oil spills on land can cause degradation-quality, declining soil productivity and environmental pollution. Land degradation will make a major contribution to the aggravation of the environmental quality in general. So it is necessary to attempt to determine its total organic carbon 
content of the soil and lead metal in the soil. One of the methods that can be applied is the potentiometric and voltammetry methods using ion selective electrodes[9].

Ions Selective Electrode (ESI) are membrane electrodes that respond selectively ion. These include probes that measure specific ions and gases in solution. ESI is the most commonly used $\mathrm{pH}$ probe. Ions that can be measured include fluoride, bromide, cadmium, and gases in solution such as ammonia, carbon dioxide, and nitrogen oxides. Use of Ion Selective Electrodes in environmental analysis offers several advantages over other methods of analysis[4].

ESI determination is not subject to interference as the colour in the sample. There are several matrix modifications needed to perform this analysis. This makes them ideal for clinical use (blood gas analysis) where they are the most popular, however, they have found practical application in the analysis of environmental samples, often where the insitu determination of necessary and not practical with other methods. A large number of indicator electrodes with good selectivity for a particular ion is based on the measurement of the potential generated across the membrane[7]. Electrodes of this type is referred to as ion-selective electrodes. Membranes are usually attached to the end of the tube that contains an internal reference electrode. This electrode membrane and an external reference electrode is then immersed in a solution of interest. Because of the potential of the two reference electrodes is constant, any change in cell potential due to potential changes across the membrane[9].

Potentiometric is one way electrochemical ion analysis based on the quantitative measurement of the electrode potential-sensitive ion concerned. Potentiometric used to determine the concentration of ions, $\mathrm{pH}$ of the solution, and the end point of the titration[5].

Elements are used in the potentiometric indicator electrode and electrodes comparator, and a salt bridge solution is analyzed. Comparison electrode is divided into two, namely primary and comparison electrodes secondary reference electrode (calomel electrode and silver electrode).

Indicator electrode is divided into two, namely the metal electrodes and membrane electrode. Metal electrode consists of three kinds, among other types of electrodes first, second, and third. While the membrane electrode is divided into glass membrane electrode, the membrane electrode solid, liquid membrane electrodes and membrane electrode gas[3].

The principle of the determination of total organic carbon content of the soil with the potentiometric method is to convert the carbon compounds to $\mathrm{CO}_{2}$. Furthermore, the resulting $\mathrm{CO}_{2}$ concentrations could be measured with a selective electrode potentiometric $\mathrm{CO}_{2}$ as an indicator electrode. $\mathrm{CO}_{2}$ selective electrode composed of outer membrane that is permeable to $\mathrm{CO}_{2}$ gas, the internal $\mathrm{pH}$ electrode, electrode and electrolyte solution which comparison is between the membrane and the internal $\mathrm{pH}$ electrode. When the body of $\mathrm{CO}_{2}$ selective electrode dipped into the analyte solution, the $\mathrm{CO}_{2}$ from the solution of the analyte diffuses across the membrane toward the internal electrolyte solution. In the internal electrolyte solution $\mathrm{CO}_{2}$ hydrolysis reactions produce $\mathrm{H}_{3} \mathrm{O}^{+}$ions are potential response by internal $\mathrm{pH}$ electrode. Potential response is proportional to the activity or concentration of $\mathrm{CO}_{2}$ in the analyte solution[6].

If the measured solution containing other species with species-specific concentration, the $\mathrm{CO}_{2}$ selective electrode also responds to the species-species, so the resulting potential is the potential simultaneously.

\section{EXPERIMENTAL}

Potential response measurement results of the oxidation of C- $\mathrm{CO}_{2}$ total organic soil with a solution of $\mathrm{KMnO}_{4}$ with acidic conducted by three (3) parameters, namely the weight of the soil sample and the volume of $\mathrm{H}_{2} \mathrm{SO}_{4}$ anyway (parameters), the large and varied sample volume remains $\mathrm{H}_{2} \mathrm{SO}_{4}$ (parameter 2), and the sample weight remains but volume of $\mathrm{H}_{2} \mathrm{SO}_{4}$ varied (parameter 3 ). From the results of these measurements obtained the right conditions for the measurement of total organic carbon concentration of the soil, either by potentiometric and titrimetric methods. For the determination of the potentiometric method, 2 grams of dried soil sample put into a glass beaker containing $25 \mathrm{~mL} 0.1 \mathrm{M}$ $\mathrm{H}_{2} \mathrm{SO}_{4}$, and then titrated with $0.1 \mathrm{M}$ in excess $\mathrm{KMnO}_{4}$ while stirring and $\mathrm{CO}_{2}$ were measured with selective electrodes. The potential value then put into the equation of the regression line of the calibration curve was created. Titrimetric method for the measurement, the sample was measured potential is then filtered and the filtrate titrated behind with $0.1 \mathrm{M}$ oxalic acid until the equivalence point is reached. Content total soil organic carbon is determined based on the amount of $\mathrm{KMnO}_{4}$ are required to oxidize the total organic $\mathrm{C}$ to $\mathrm{CO}_{2}$.

The performance parameters of the analysis of measurements carried out through several tests, namely: accuracy, precision, sensitivity, detection limit and repeatability of measurements[10].

\section{RESULT AND DISCUSSION}

\section{A. Response time of selective electrode $\mathrm{CO}_{2}$}

The results showed potential response of selective electrode $\mathrm{CO}_{2}$ reaches a maximum value ranging $3^{\text {rd }}$ minute with a steady state period for 50 seconds, in line with the formation of $\mathrm{CO}_{2}$, after which the potential response slowly began to fall back because the $\mathrm{CO}_{2}$ released into the air as a result of stirring constantly. Values maximum potential and potential response time of $\mathrm{CO}_{2}$ can be seen in Table 1 .

The $\mathrm{pH}$ greatly affect the stability of $\mathrm{CO}_{2}$ in the analyte solution which in turn affects the potential response. The graph of potential $(\mathrm{mV})$ against $-\log \left[\mathrm{CO}_{2}\right]$ of the data in the table produces a linear curve at $\mathrm{pH} 4$ to 6 by a factor of between 50.5 to 54.5 Nernst $\mathrm{mV} /$ decade. The optimum conditions obtained at $\mathrm{pH} 53$ with the Nernst factor $\mathrm{mV} /$ decade. This situation is related to the stability of $\mathrm{CO}_{2}$ in solution. In acidic conditions, the $\mathrm{CO}_{2}$ is in the form $\mathrm{H}_{2} \mathrm{CO}_{3}$, whereas under alkaline conditions will be changed to $\mathrm{HCO}_{3}$ Potential response can be seen in Fig.1.

TABLE I

Response Time Of Selective Electrode CO2 In VARIOUS CONCENTRATIONS OF CO2 


\begin{tabular}{|c|c|c|}
\hline$\left[\mathrm{CO}_{2}\right](\mathrm{M})$ & Potential $(\mathrm{mV})$ & $\begin{array}{c}\text { Time } \\
\text { (minutes) }\end{array}$ \\
\hline $5,25 \times 10^{-1}$ & 90,2 & 3 \\
$3,13 \times 10^{-1}$ & 82,7 & 3 \\
$9,87 \times 10^{-2}$ & 57 & 3 \\
$5,24 \times 10^{-2}$ & 39,0 & 3 \\
$9,67 \times 10^{-3}$ & 5,1 & 3 \\
$5,34 \times 10^{-3}$ & $-10,6$ & 3 \\
$9,67 \times 10^{-4}$ & -39 & 3 \\
$5,05 \times 10^{-4}$ & $-45,3$ & 3 \\
$9,98 \times 10^{-5}$ & -57 & 3 \\
$5,16 \times 10^{-5}$ & $-59,5$ & 3 \\
$9,63 \times 10^{-6}$ & $-61,9$ & 3 \\
$5,83 \times 10^{-6}$ & $-63,2$ & 3 \\
\hline
\end{tabular}

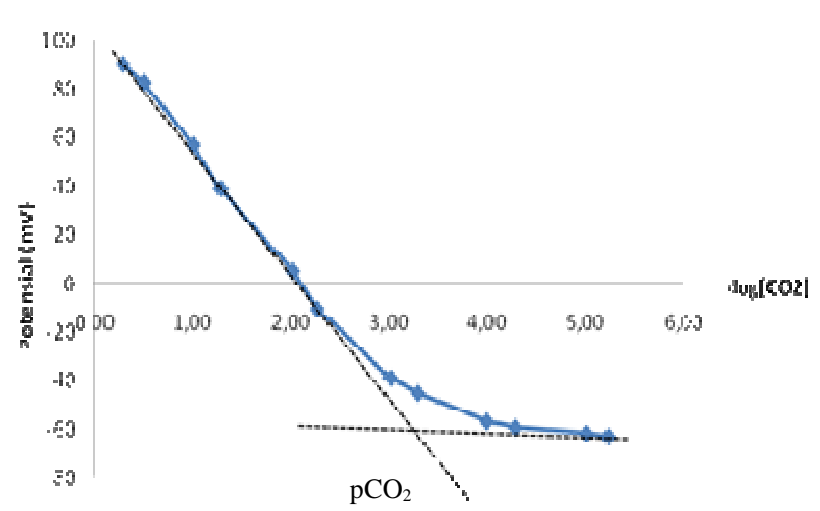

Fig. 1 The graph of potential against $-\log \left[\mathrm{CO}_{2}\right]$

\section{B. Range concentration measurement, the Nernst factor and detection limit}

From the data listed in Table 1, when made a graph that connects potential values $(\mathrm{mV})$ against $-\log \left[\mathrm{CO}_{2}\right]$ sigmoid shaped graphs obtained with the linear curve in the concentration range $9,67 \times 10^{-4}$ until $3,13 \times 10^{-1} \mathrm{M}$ as an area of concentration (stretch) measurements. Thus selective electrode $\mathrm{CO}_{2}$ only feasible for $\mathrm{CO}_{2}$ measurement in that concentration range Nernst factor (slope) of the curve linier is $50 \mathrm{mV} /$ decade, while the detection limit is $4 \times 10^{-4} \mathrm{M}$, so for $\mathrm{CO}_{2}$ with a concentration of less than that value cannot be measured potential significantly.

\section{Calibration curve}

Calibration curve obtained from the graph of potential $(\mathrm{mV})$ against $-\log \left[\mathrm{CO}_{2}\right]$ from the data in Table 2 the yield line equation $\mathrm{Y}=-59,28 \mathrm{X}+180,2$ and linearity of the line 0,992 . Linearity of the line $\mathrm{Y}=\mathrm{CO}_{2}$ potential and $\mathrm{X}=-\log$ $\left[\mathrm{CO}_{2}\right]$. This curve is used for the determination of total organic carbon by potentiometric method. Calibration curve approaching the Nernst equation can be seen in Fig. 2 .

\begin{tabular}{|c|c|c|}
\hline$\left[\mathrm{CO}_{2}\right](\mathrm{M})$ & $\mathrm{pCO}_{2}$ & $\mathrm{E}(\mathrm{mV})$ \\
\hline 0,1 & 1 & 118,3 \\
$5.10-2$ & 1,303 & 99,6 \\
$5.10-2$ & 2 & 66,9 \\
$5.10-3$ & 2,3030 & 49,8 \\
$5.10-3$ & 3 & 3,0 \\
$5.10-4$ & 3,301 & $-21,2$ \\
\hline
\end{tabular}

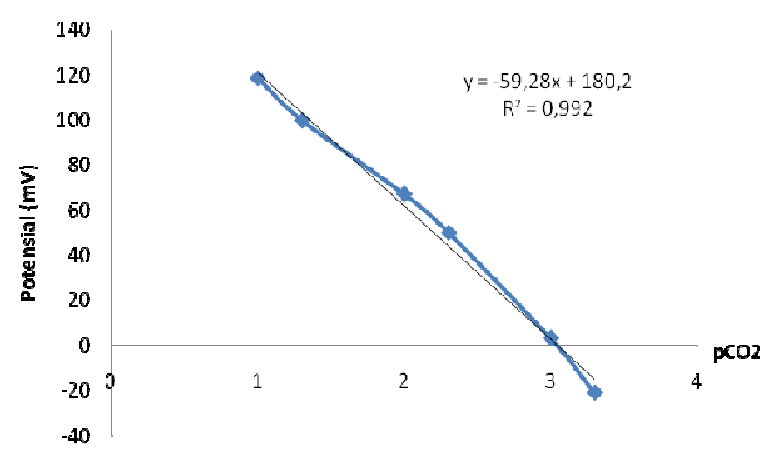

Fig. $2 \mathrm{CO}_{2}$ concentration curve approaching the Nernst equation

\section{Content of total organic carbon in the soil}

The results of measurements of the optimum conditions of soil samples with 3 parameters, shows that for the degradation of the total soil organic carbon to $\mathrm{CO}_{2}, \mathrm{KMnO}_{4}$ absolutely necessary, while the greater number of soil samples that degraded the more $\mathrm{KMnO}_{4}$ are needed, so that the greater the concentration of $\mathrm{CO}_{2}$ is produced. The amount of $\mathrm{H}_{2} \mathrm{SO}_{4}$ is best for the ongoing degradation of 2 grams of soil sample with $30 \mathrm{~mL}$ of $\mathrm{KMnO} 4$. In this condition the potential value of $\mathrm{CO}_{2}$ reaches the largest value which means the process of redox reactions take place most effectively

By entering the potential value contained in Table 2 to the linear equation $\mathrm{Y}=-59,28 \mathrm{X}+180.2$, was obtained at the same $\mathrm{CO}_{2}$ concentration of total organic carbon concentration of four soil samples from different places with successive potentiometric method is $0.045 \%, 0.06 \%$, $0.056 \%$, and $0.01 \%$. Titrimetric measurement method is $0.097 \%, 0.147 \%, 0.120 \%$, and $0.071 \%$. The difference in these results suggest that the determination of the total soil organic carbon by potentiometric method is lower than the usual titrimetric method. It was alleged that $\mathrm{KMnO}_{4}$ is added not only to react with organic compounds but also reacts with inorganic reducing agents present in the soil, such as compounds of iron (II).

Thus the method of determination of total organic carbon in the soil by potentiometric method is more accurate than the titrimetric methods. 
Ions Selective Electrode of $\mathrm{CO}_{2}$ can be used to determine $\mathrm{CO}_{2}$ in a solution of the analyte at the concentration $9,09 \mathrm{x}$ $10^{-4} \mathrm{M}$ until $3,4 \times 10^{-1} \mathrm{M}$, the Nernst factor on temperature $25^{\circ} \mathrm{C}$ at $53 \mathrm{mV} /$ decade and a detection limit $5 \times 10^{-4} \mathrm{M}$, while the potential measurement conditions of $\mathrm{CO}_{2}$ is best done at $\mathrm{pH} 5$.

Potentiometric method can be used as an alternative method that is more accurate than the titrimetric method for the determination of total carbon content of the soil.

\section{ACKNOWLEDGMENT}

We thank to the Research and Community Service of Directorate General of High Education for financially supporting this research through Competitive Grant Research Program of budget Year 2014 and State Polytechnic of Sriwijaya that has supported this research.

\section{REFERENCES}

[1] Herned, H.S. and Raymond. J. Am. Soc., 65, pp. 2030-2037, 1943.

[2] Cottenie, A., Soil and Management of Soil in the Tropics, Jon Wiley \& Sons, New York, 1976.

[3] Maryanto, J., Determination of total organic carbon content of soil by spectrophotometric and titrimetric methods, Thesis, Master Degree in chemistry, Institute of Technology Bandung, 1993.

[4] Jensen, M.A. and Revhnitz, Response time characteristic of the pCO2 electrode, Anal. Chem. 51(12), 1979.

[5] Haris, A., Buchari, Studies on the application of the potentiometric method of determining the total organic carbon content of soil, JMS Vol. 5 (1), pp. 23-40, 2000.

[6] Bow, Yohandri, Determination of phenol compounds using electrodes coated with enzymes, J. Kinetika, Vol. 2(2). 2009

[7] Bow, Yohandri, Preparation of Carbon Zeolite Composite Electrode for Determination of Phenol Compounds. J. Teknika, Vol.xix(1), 2007

[8] Bow, Yohandri, Modified carbon composite electrode with zeolite in degradation of dissolved chlorine, in Proc. ChESA, 2013, p.49-54

[9] Bard, A.J., Faulkner, L. R, Electrochemical methods: Fundamental and Application 2ed. Wiley. 2000.

[10] Kissinger, peter, William, R. Heineman Laboratory Techniques in Electroanalytical Chemistry, Sec. ed, Revised and Expanded (2 ed), CRC, 1996 